\title{
Subdural hematomas in 1846 patients with shunted idiopathic normal pressure hydrocephalus: treatment and long-term survival
}

\author{
Nina Sundström, MScEP, PhD, ${ }^{1}$ Marcus Lagebrant, MD, ${ }^{2}$ Anders Eklund, MScEP, PhD, ${ }^{1}$ \\ Lars-Owe D. Koskinen, MD, PhD, ${ }^{2}$ and Jan Malm, MD, PhD²
}

Departments of ${ }^{1}$ Radiation Sciences, Biomedical Engineering, and ${ }^{2}$ Pharmacology and Clinical Neuroscience, Umeå University, Umeå, Sweden

\begin{abstract}
OBJECTIVE Subdural hematoma (SDH) is the most common serious adverse event in patients with shunts. Adjustable shunts are used with increasing frequency and make it possible to noninvasively treat postoperative SDH. The objective of this study was to describe the prevalence and treatment preferences of SDHs, based on fixed or adjustable shunt valves, in a national cohort of patients with shunted idiopathic normal pressure hydrocephalus (iNPH), as well as to evaluate the effect of SDH and treatment on long-term survival.

METHODS Patients with iNPH who received a CSF shunt in Sweden from 2004 to 2015 were included in a prospective quality registry $(n=1846)$ and followed regarding SDH, its treatment, and mortality. The treatment of SDH was categorized into surgery, opening pressure adjustments, or no treatment.

RESULTS During the study period, the proportion of adjustable shunts increased from $75 \%$ to $95 \%$. Ten percent $(n=$ 184) of the patients developed an SDH. In 103 patients, treatment was solely opening pressure adjustment. Surgical treatment was used in 66 cases (36\%), and $15(8 \%)$ received no treatment. In patients with fixed shunt valves, 90\% (n $=17)$ of SDHs were treated surgically compared with $30 \%(n=49)$ in patients with adjustable shunts $(p<0.001)$. There was no difference in long-term patient survival between the SDH and non-SDH groups or between different treatments.

CONCLUSIONS SDH remains a common complication after shunt surgery, but adjustable shunts reduced the need for surgical interventions. SDH and treatment did not significantly affect survival in this patient group, thus the noninvasive treatment offered by adjustable shunts considerably reduces the level of severity for this common adverse event.

https://thejns.org/doi/abs/10.3171/2017.5.JNS17481
\end{abstract}

KEY WORDS cerebrospinal fluid shunt; complications; hydrocephalus; normal pressure; subdural hematoma; survival; treatment

$\mathrm{S}$ UBDURAL hematoma (SDH)/hygroma, considered to be a serious adverse event, is one of the most common complications in patients receiving shunts due to idiopathic normal pressure hydrocephalus (iNPH). ${ }^{18}$ Symptoms due to SDH have a broad range, from being asymptomatic and only revealed on $\mathrm{CT}$, to mass lesions with hemiparesis and coma. The prognosis varies accordingly. ${ }^{14}$ The risk of patients with iNPH developing an SDH after shunt surgery is related to physiological properties, such as brain compliance, ventricular size, and drainage capacity of the shunt. ${ }^{5,16}$ Studies have concluded that a low opening pressure of the shunt increases the risk of SDH. ${ }^{1}$
The use of adjustable shunt valves is increasing worldwide. In an adjustable CSF shunt, the opening pressure can be downregulated noninvasively for further clinical improvement, or upregulated if there are symptoms or signs of overdrainage. ${ }^{10,19}$ The traditional treatment of SDH is surgical, including evacuation of the hematoma through bur holes or craniotomy and/or ligation or removal of the shunt. ${ }^{6}$ Here, the adjustable shunt valves offer a noninvasive option. Hospital-based case series have shown that raising the opening pressure may be an efficient method of SDH treatment..$^{2,8,11,13}$ However, in a general population, it is unknown whether the use of adjustable shunt valves

ABBREVIATIONS iNPH = idiopathic normal pressure hydrocephalus; NPR = National Population Registry; SDH = subdural hematoma; SHDR = Swedish Hospital Discharge Registry; SHQR = Swedish Hydrocephalus Quality Register.

SUBMITTED February 23, 2017. ACCEPTED May 8, 2017.

INCLUDE WHEN CITING Published online October 27, 2017; DOI: 10.3171/2017.5.JNS17481. 
reduces the need for surgical hematoma evacuations or shunt revisions due to SDH.

The Swedish Hydrocephalus Quality Register (SHQR) is a national registry initiated in 2004 with the primary aim of monitoring and supporting improvement of quality of hydrocephalus care in Sweden. Similar registries also exist in several other countries. ${ }^{4,712}$ At the date of data retrieval for this study (September 1, 2015), more than 4000 patients who had undergone operations due to hydrocephalus were included in the registry. We hypothesized that postoperative adjustment of the opening pressure of adjustable shunts has become an established way of treating $\mathrm{SDH}$ in Sweden. A second hypothesis was that long-term survival in patients with iNPH and an SDH is independent of treatment but less favorable than in those without an $\mathrm{SDH}$. We evaluated the prevalence of SDHs, how these were treated, and the effect on long-term survival based on data from the SHQR.

\section{Methods}

More than 1800 patients with iNPH treated with shunt surgery in Sweden between 2004 and 2015 were included when evaluating the occurrence of SDH complications. All neurosurgical departments in Sweden participate in the SHQR in which data regarding patients undergoing hydrocephalus surgery is prospectively collected. SHQR contains information about clinical features and investigations before surgery, the surgical procedure, and information about the shunt and postoperative follow-up ( 3 and 12 months postoperatively), including adverse events and shunt revisions. To obtain information regarding diagnosis and mortality, data were also retrieved from two other national databases and patient identities cross-referenced to the SHQR.

The ethics committee at Umeå University approved the study. When a decision to undergo surgery is made, the patients are informed about their inclusion in the registry, and exclusion is always allowed.

\section{Study Population}

Since its inception on January 1, 2004, 4011 patients were registered in the SHQR. Patients undergoing endoscopic third ventriculostomy ( $\mathrm{n}=452)$, as well as patients receiving a diagnosis other than iNPH $(n=1713)$, were excluded. The final study population consisted of $1846 \mathrm{pa}-$ tients with iNPH treated with a ventriculoperitoneal CSF shunt. Data were collected from 3 national registries: 1) the SHQR, 2) the Swedish Hospital Discharge Registry (SHDR), and 3) the National Population Registry (NPR, equivalent to the National Inpatient Sample database in the US $\left.{ }^{15}\right)$. The baseline characteristics of included patients are described in Table 1 and the inclusion process in Fig. 1. The occurrence of an SDH was confirmed by CT of the brain when new symptoms appeared after shunt surgery or at scheduled follow-up at 3 and 12 months after surgery.

\section{Registry Data and Validation}

Age, sex, study site, date of surgery, type of shunt valve, presence of an antisiphoning device, adverse events, opening pressure adjustments, and shunt revisions were re-
TABLE 1. Baseline characteristics of included patients

\begin{tabular}{lcc}
\hline \multicolumn{1}{c}{ Variable } & Total & SDH \\
\hline Patients, no. (\%) & 1846 & $184(10.0)$ \\
\hline Males/females, no. (\%) & $1109 / 737(60.1 / 39.9)$ & $131 / 53(11.8 / 7.2)$ \\
\hline Mean age in yrs (SD) & $73.3(7.7)$ & $72.1(8.4)$ \\
\hline Adjustable shunts, no. (\%) & $1636(88.6)$ & $165(10.1)$ \\
\hline Strata & 1027 & $106(10.3)$ \\
\hline $\begin{array}{l}\text { Codman Hakim program- } \\
\text { mable valve }\end{array}$ & 486 & $44(9.1)$ \\
\hline $\begin{array}{l}\text { Codman Hakim pro- } \\
\text { grammable valve w/ }\end{array}$ & 56 & $11(19.6)$ \\
$\quad \begin{array}{c}\text { SiphonGuard } \\
\text { Codman Certas program- } \\
\text { mable valve }\end{array}$ & 18 & $3(16.7)$ \\
\hline Miethke & 5 & - \\
\hline Unknown & 44 & $1(2.3)$ \\
\hline Fixed shunts, no. (\%) & $203(11.0)$ & $19(9.4)$ \\
\hline Delta & 58 & $6(10.3)$ \\
\hline $\begin{array}{l}\text { Codman Hakim precision } \\
\text { fixed-pressure valve }\end{array}$ & 136 & $13(9.6)$ \\
\hline Unknown & 9 & - \\
\hline \begin{tabular}{l} 
Unknown, no. (\%) \\
\hline
\end{tabular} & $7(0.4)$ & - \\
\hline
\end{tabular}

trieved from the SHQR. All adverse events and additional treatments/revisions following the original shunt surgery were included from the date of shunt surgery to the date of data retrieval (September 1, 2015). Opening pressures for different shunt models were transformed to $\mathrm{mm} \mathrm{H}_{2} \mathrm{O}$ for conformity. ${ }^{3,9}$ At one of the centers, a retrospective post hoc analysis on all patients undergoing surgical treatment for their SDH was performed by a senior consultant scrutinizing the patient files and CT/MR images of the brain. The combined information from these files and investigations was evaluated for symptoms and signs and classified as surgery needed or not needed.

The SHQR was manually validated against medical records for all patients found to have an SDH. External validation was also performed by searching for the ICD-10 code I62.0 ("Subdural hemorrhage") in the SHDR. Positive findings were compared with complications registered in the SHQR, and possible mismatches were adjusted on the basis of information in the medical records. Deceased patients were confirmed through the NPR.

The concentration of all surgeries to a few centers $(n=$ 7), audits between centers during the first years of registry startup, and the involvement of specific, dedicated personnel at each center registering all information in a structured manner ensured high patient coverage in the SHQR, and thus in this study.

\section{Treatment of SDH}

All patients were divided into the groups "SDH" (i.e., subdural hematoma or hygroma) and "no SDH." For the $\mathrm{SDH}$ group, treatment of SDH was categorized into 3 groups: 1) surgery, 2) opening pressure adjustments, and 3) no surgery and no adjustment. Patients having both a sur- 


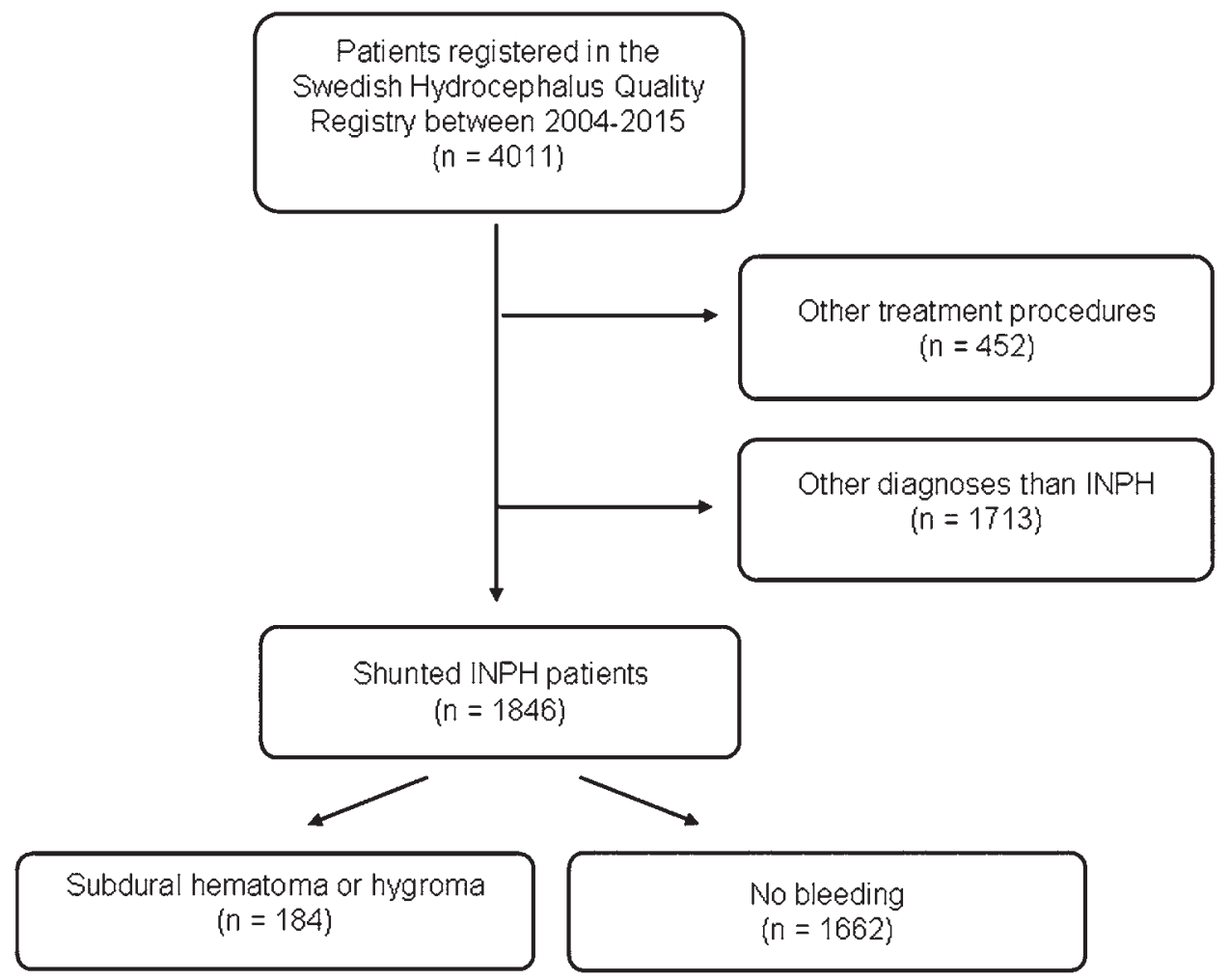

FIG. 1. Study flow chart.

gical procedure and opening pressure adjustments were categorized in the surgery group.

\section{Statistics}

Statistical analyses were performed with PASW Statistics (version 23, IBM SPSS Statistics). Continuous variables were presented as median values and quartiles (quartile 1 [Q1], Q3). The Shapiro-Wilk test was used for testing normality distribution, and the Pearson chi-square test was used for comparison between groups. Time-toevent analysis was performed using the Kaplan-Meier method, and the log-rank test was used for comparisons between groups. The significance level was set at $\alpha=0.05$.

\section{Results}

During the study period, $88.6 \%$ of patients received an adjustable shunt valve. Between 2004 and 2015, the frequency of patients receiving an adjustable shunt increased from $75 \%$ to $95 \%$, but there were considerable variations between centers (Fig. 2). In patients treated with opening pressure adjustments, an average of 1.1 adjustments were made after the SDH incident. The distribution of shunt models is described in Table 1.

Of 1846 included patients, $184(10.0 \%)$ had an SDH. The frequency of SDH did not differ between fixed and adjustable shunts ( $\mathrm{p}=0.745$, Table 1$)$, and the distribution between different neurosurgical sites is shown in Table 2 . The median time between shunt surgery and the SDH was 223 days (Q1 56, Q3 590). Figure 3A shows the SDH treatment distribution for all 184 patients having an SDH. Of these patients, 165 had an adjustable shunt valve, and in this group, $62.4 \%(n=103)$ were treated solely with opening pressure adjustments. Surgical treatment was received in $29.7 \%(n=49)$ of cases compared with $89.5 \%(n=17)$ in patients with fixed shunts $(\mathrm{p}<0.001$; Fig. $3 \mathrm{~B}$ and $\mathrm{C})$. Treatment changes over the study period (2004-2015) are presented in Fig. 4 and differences between units in Fig. 5 . The retrospective post hoc analysis of symptoms and CT/MR images revealed that $50 \%$ of the patients treated with surgery could have been treated by valve adjustment instead. This was based on the findings that the patients had no clear symptoms related to the side of the SDH and no acute bleedings on the images of the brain.

Of the 184 patients with SDH, 9.2\% ( $\mathrm{n}=17)$ experienced rebleedings. Of these, 9 were treated surgically after the first SDH, and 9 were treated surgically after the rebleeding. The others were treated conservatively or with opening pressure adjustment.

\section{Survival}

Mortality rates 1 year after an SDH complication are presented in Table 3. In all, $9.8 \%$ of patients $(n=18)$ died within 1 year after SDH. Only 2 died less than 1 month after the complication date. No significant difference in mortality was observed between treatment groups. In Fig. 6 , the cumulative long-term survival rate for all patients is shown. There was no significant difference between the SDH and non-SDH groups ( $p=0.593$, Fig. 6A), nor was there any difference in survival between the 3 treatment groups $(\mathrm{p}=0.875$, Fig. $6 \mathrm{~B})$ or between the different centers $(\mathrm{p}=0.119$, Fig. $6 \mathrm{C})$. 


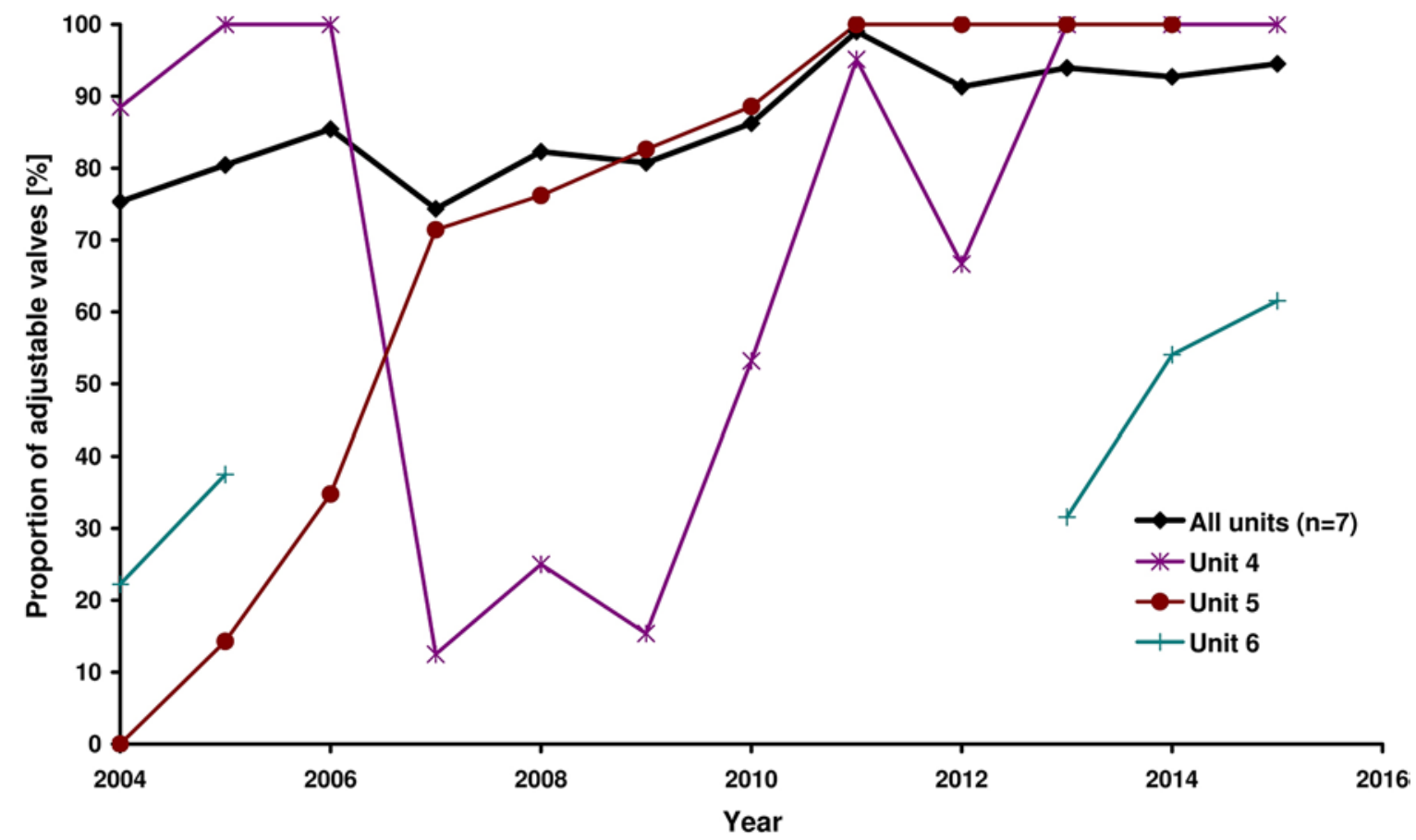

FIG. 2. Graph of the proportion of patients who underwent operations with adjustable shunt valves during the study period (January 1,2004 , to September 1, 2015). For illustrative purpose, all units using only adjustable valves during the entire study period (Units 1, 2, 3, and 7) are not displayed. Figure is available in color online only.

\section{Discussion}

Small case series indicate that surgical hematoma evacuations and shunt revisions could be avoided by using adjustable shunt valves. ${ }^{2,8,11,13}$ This hypothesis was supported in this large patient cohort, and the long-term survival associated with SDH and different treatment options was evaluated. We found that the use of adjustable shunts is well established and increasing in Sweden and that most SDHs are treated by opening pressure adjustments when adjustable shunts are present. It was also shown that neither the occurrence of an SDH nor the choice of treatment significantly affected long-term patient survival.

\section{Treatment of SDH}

Shunt surgery is a common treatment for iNPH, and the incidence of surgery has increased over the last decade. ${ }^{17}$ In Sweden, adjustable shunt valves have been used to a varying extent since the beginning of the $1990 \mathrm{~s},{ }^{20}$ and when fixed valves are still applied, it is often for shortterm economic reasons. Considering that SDHs were as common in patients having fixed as well as adjustable shunts, health economics investigations might well prove adjustable shunts to be a less expensive option despite their higher purchase price. Thus, if the entire care situation is evaluated, including the cost of surgical versus shunt adjustment treatment for $\mathrm{SDH}$, adjustable shunts are likely to be a valuable option in the long run.

Most Swedish neurosurgical departments used adjustable shunts during the study period. Although 1 center reverted back to fixed valves during 2007-2009, the overall

TABLE 2. Differences between university hospitals in Sweden

\begin{tabular}{|c|c|c|c|c|c|}
\hline \multirow{2}{*}{$\begin{array}{l}\text { Neurosurgical } \\
\text { Unit }\end{array}$} & \multirow{2}{*}{$\begin{array}{l}\text { No. of iNPH Patients Receiving } \\
\text { Shunts During Study Period }\end{array}$} & \multicolumn{3}{|c|}{ No. of iNPH Patients w/ Adjustable Shunts (\%) } & \multirow{2}{*}{$\begin{array}{l}\text { No. of iNPH Patients w/ } \\
\text { SDH or Hygroma (\%) }\end{array}$} \\
\hline & & Yes & No & Unknown & \\
\hline 1 & 571 & $569(99.6)$ & - & $2(0.4)$ & $60(10.5)$ \\
\hline 2 & 220 & $220(100)$ & - & - & $17(7.7)$ \\
\hline 3 & 309 & $309(100)$ & - & - & $49(15.9)$ \\
\hline 4 & 398 & $296(74.4)$ & $102(25.6)$ & - & $35(8.8)$ \\
\hline 5 & 217 & $162(74.7)$ & $51(23.5)$ & $4(1.8)$ & $16(7.4)$ \\
\hline $6^{*}$ & 99 & $47(47.5)$ & $51(51.5)$ & $1(1.0)$ & $7(7.1)$ \\
\hline $7 \dagger$ & 32 & $32(100)$ & - & - & - \\
\hline All units & 1846 & 1635 (88.6) & $204(11.0)$ & $7(0.4)$ & $184(10.0)$ \\
\hline
\end{tabular}



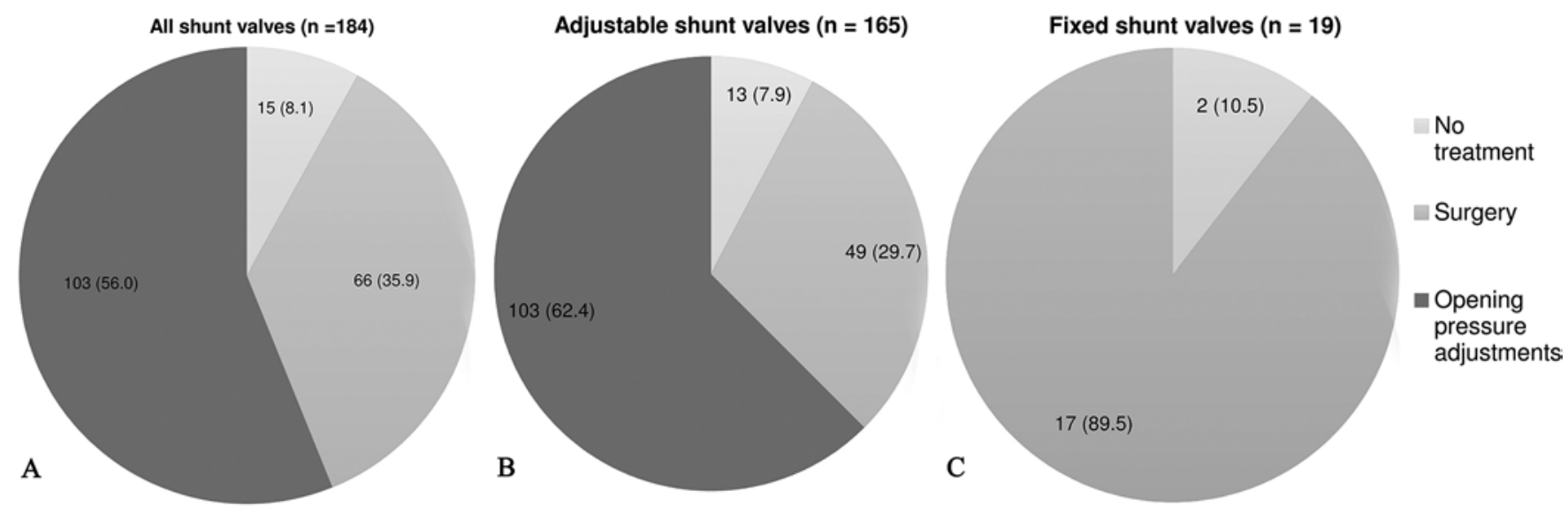

FIG. 3. Pie charts showing the treatment of SDH depending on shunt valve type: all shunt valves (A), adjustable shunt valves (B), and fixed shunt valves (C). Data given as number of patients (\%).

use of fixed valves diminished steadily (Fig. 2). Interestingly, the application of opening pressure adjustment for treating SDH did not follow the same pattern but rather the opposite one (Fig. 4). In this instance, part of the explanation is the inclusion of more fixed shunt valves during 2013-2015 when Unit 6 restarted their registration in the SHQR.

Thus, most SDHs could be treated by an adjustment of the shunt opening pressure, and this was also the case, confirming the hypothesis that noninvasive postoperative adjustment has become an established way of treating SDHs in Sweden. While $90 \%$ of patients with an SDH and a fixed shunt valve were treated surgically, $30 \%$ of those having adjustable shunts were still surgically treated. The post hoc analysis of the need for surgery as compared with opening pressure adjustment also revealed that, according to the clinical and imaging pictures, the noninvasive option could have been applied to a higher degree. It is likely that tradition and lack of scientific evidence regarding the effect of the noninvasive option played an important part in the physician's choice of treatment, favoring surgery in complex cases instead of considering shunt adjustment as a first step.

The frequency of SDHs found in this study (10\%) is low compared with a previous Swedish study ${ }^{19}$ but higher than the average of $6.3 \%$ (range $2 \%-47 \%$ ) presented in

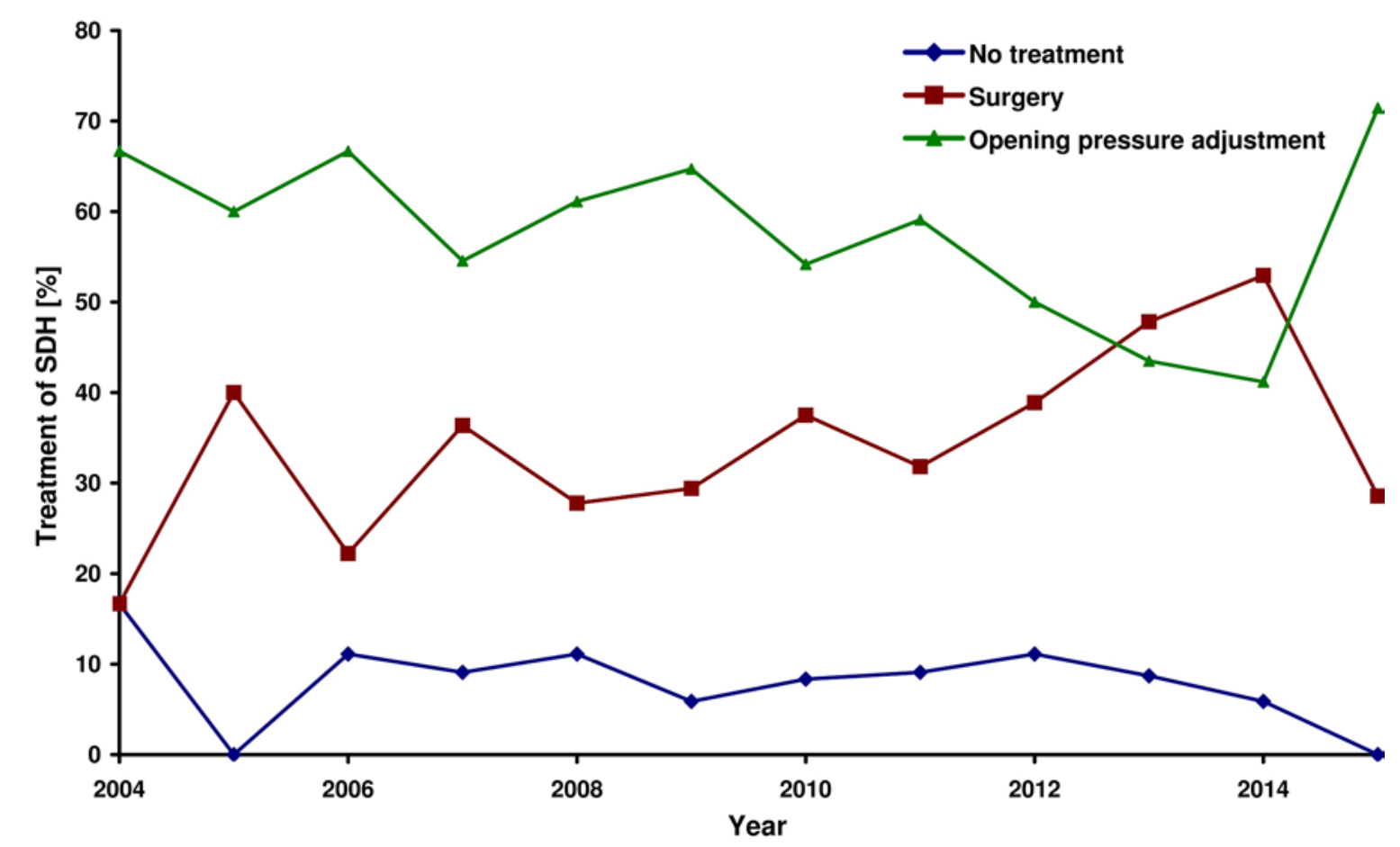

FIG. 4. Proportion of treatment regimens of SDH between 2004 and 2015 for fixed as well as adjustable shunts. The total number of patients treated for SDH each year were $6,5,9,11,18,17,24,22,18,23$, 17, and 14, respectively. Figure is available in color online only. 


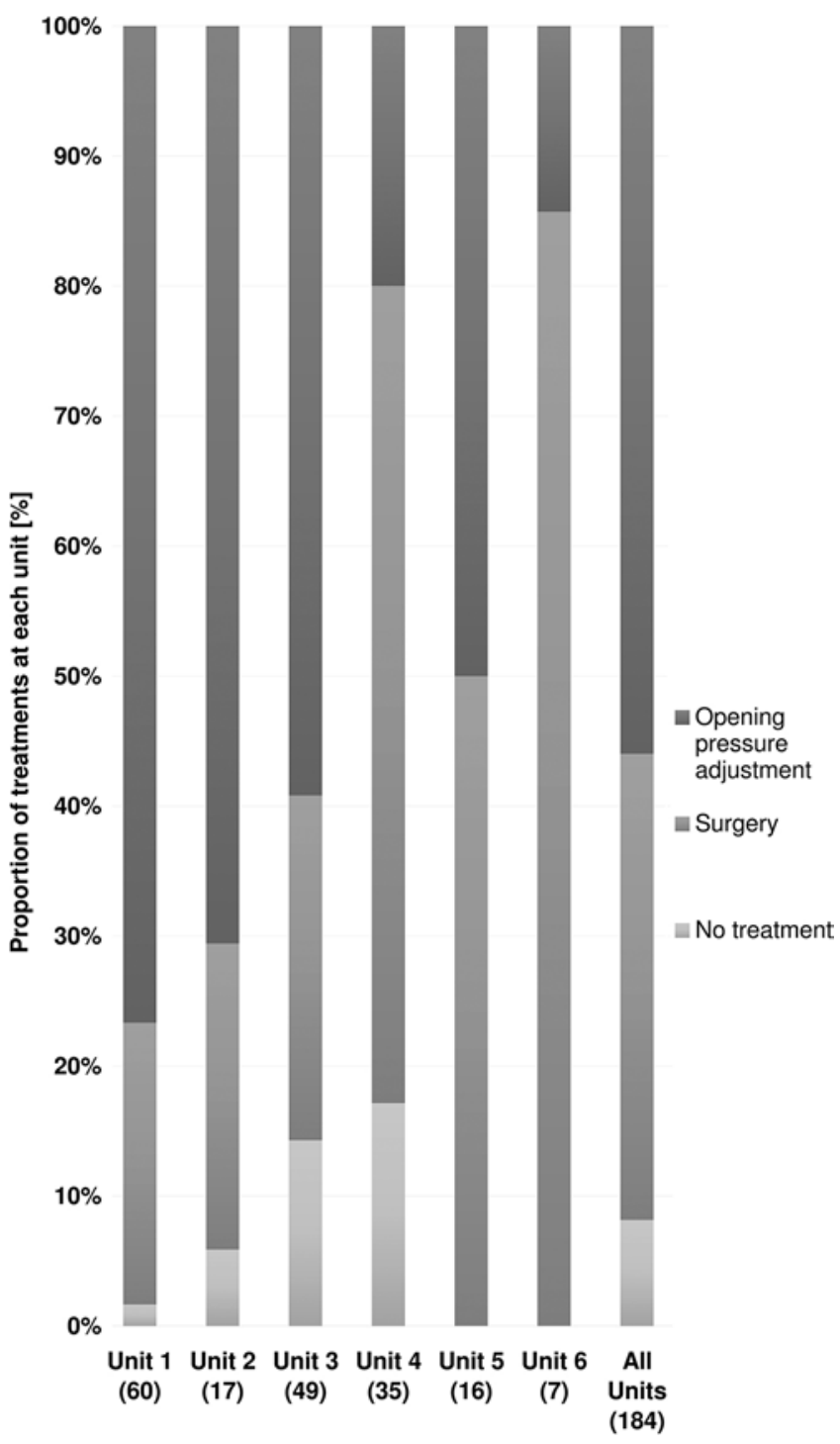

FIG. 5. Difference in treatment of SDH between neurosurgical units. Only 6 centers are presented because in the seventh center no SDH occurred. The number of patients with SDH at each neurosurgical unit are shown in parentheses.

a recent systematic review. ${ }^{18}$ However, the true incidence is uncertain due to follow-up routines. Most SDHs also occurred within the first year after shunt surgery, which emphasizes the importance of postoperative follow-up in this patient group.

\section{Survival}

The 1-year mortality rate and long-term survival rate did not differ significantly between patients with and without an SDH nor between treatment groups. Long-term survival stratified by center also revealed no significant differences. The seemingly higher cumulative survival in Unit 6 is likely due to low patient inclusion $(n=99)$ mainly during the last 3 years of the study period (2013-2015), thus rendering few cases of $\mathrm{SDH}(\mathrm{n}=7)$ and all but 1 being censored. Based on the substantial study population, this suggests that SDHs have a limited effect on survival in
TABLE 3. Mortality in the SDH group 1 year after complication date

\begin{tabular}{lcr}
\hline \multirow{2}{*}{ Treatment Group } & \multicolumn{2}{c}{$\begin{array}{c}\text { No. of Patients } 1 \mathrm{Yr} \\
\text { After Surgery }(\%)\end{array}$} \\
\cline { 2 - 3 } & Dead & Alive \\
\hline No treatment $(\mathrm{n}=15)$ & $2(13.3)$ & $13(86.7)$ \\
\hline Surgery $(\mathrm{n}=66)$ & $8(12.1)$ & $58(87.9)$ \\
\hline Opening pressure adjustments $(\mathrm{n}=103)$ & $8(7.8)$ & $95(92.2)$ \\
\hline There was no significant difference in mortality between the treatment groups.
\end{tabular}

patients with iNPH and shunts. Thus, a noninvasive treatment appears to be as favorable as surgery but with fewer cosmetic disadvantages. The risk of rebleeding and infection could probably also be reduced, while likely gaining higher cost-effectiveness. The significantly higher proportion of noninvasive treatments in the group with adjustable shunts also indicates that, if patients with fixed valves had received adjustable shunts instead, it is most likely that many surgical procedures could have been avoided.

Although not significant, the mortality rate 1 year after a complication was higher in the patient group undergoing surgery than in the group treated with opening pressure adjustments. This suggests that a nonsurgical treatment could be preferable to a surgical one. There are, however, many factors influencing the outcome for patients in the $\mathrm{SDH}$ group, not the least of which is the complication itself. Subdural collections constitute a heterogeneous group of clinical conditions, and a large SDH with a mass effect is more likely to be treated with evacuation of the hematoma, whereas an asymptomatic hygroma is more likely to be treated by opening pressure adjustments (if an adjustable shunt valve is present).

\section{Limitations of the Study}

The SHQR prospectively collects data from all patients in Sweden who undergo operations due to hydrocephalus, and trends over time as well as between hospitals may be followed for comparison of treatments. The high coverage of the SHQR, and thus a large study population, supports the reliability of the results. The use of 3 different registries to verify data accuracy also ensures high accuracy of the treatments applied and complications occurring. However, SDHs are mainly diagnosed on follow-up CT examinations or when symptomatic; thus, it is likely that the true incidence of SDHs is even higher due to undiagnosed asymptomatic cases. However, because these are asymptomatic, they may be regarded as clinically less important.

Due to differing routines in clinical follow-up, changes in cardinal symptoms following SDH could not be evaluated in this study. Long-term survival is a very broad outcome variable; unfortunately, it does not mirror minor improvement/deterioration over time, which is likely to affect the quality of life of the patient. On the other hand, long-term survival is a well-defined parameter that reflects the success rate of the treatment, and its assessment is highly reliable. We also suspect that the number of opening pressure adjustments following SDH might be somewhat underestimated. For this simple procedure, no- 

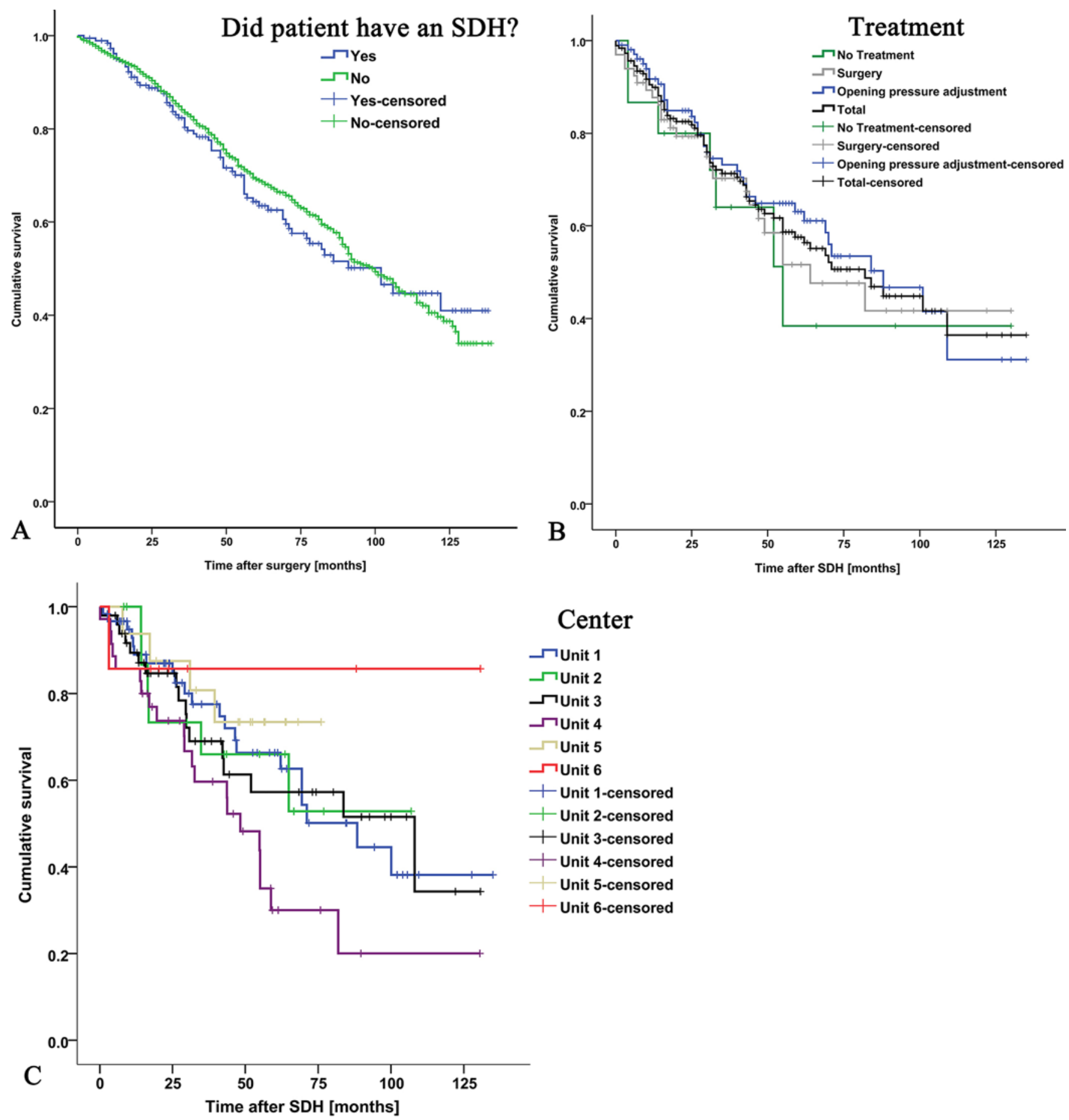

FIG. 6. Kaplan-Meier plots. A: Graph showing cumulative survival rate from date of surgery for patients with shunted iNPH and SDH (blue) and without SDH (green; $p=0.593$ ). B: Graph showing cumulative survival rate from date of SDH complication for patients with shunted iNPH receiving no treatment (green), surgery (gray), and opening pressure adjustment (blue; $p=0.875$ ). C: Graph showing cumulative survival rate from the date of SDH complication for each of the 6 units having SDH complications $(p=0.119)$. Figure is available in color online only.

tations into the medical journal might not be performed for all adjustments, making registration into the SHQR more difficult.

A limitation of this study is that it was not possible to make a distinction between SDH and hygroma. Due to their clinically similar manifestations, the SHQR has cho- sen not to separate them; thus, SDH and hygroma had to be treated as one entity in this study.

It may be difficult to dissociate the effect of center or surgeon from the effect of the valve system. However, this multicenter study reflects the general situation within the health care system in Sweden and it includes 7 different 
neurosurgical units and several surgeons in each hospital. Thus, the fixed/adjustable valves were distributed over many hospitals and surgeons, and this likely eliminated any systematic effects rendered from a specific center/surgeon on the overall outcome.

\section{Conclusions}

SDHs are common complications in patients with iNPH and shunts, and in Sweden the proportion of patients who undergo operations to receive an adjustable shunt valve has increased steadily during the period from 2004 to 2015. Upregulation of the shunt opening pressure has become an established method of treatment of SDH, and mortality analysis shows that neither subdural collections nor choice of treatment reduce the survival rate in this patient group. Health economics investigations are warranted to prove the overall advantage of adjustable shunt valves from an economic viewpoint. Thus, because SDHs can be treated noninvasively, one of the complications most commonly associated with shunt surgery in patients with iNPH might not be categorized as a serious adverse event after all.

\section{Acknowledgments}

For their continuous and meticulous work with registering every operated hydrocephalus patient in the SHQR over the years, all registrars and clinicians at each participating center are gratefully acknowledged.

\section{References}

1. Boon AJ, Tans JT, Delwel EJ, Egeler-Peerdeman SM, Hanlo PW, Wurzer HA, et al: Dutch Normal-Pressure Hydrocephalus Study: randomized comparison of low- and mediumpressure shunts. J Neurosurg 88:490-495, 1998

2. Carmel PW, Albright AL, Adelson PD, Canady A, Black P, Boydston W, et al: Incidence and management of subdural hematoma/hygroma with variable- and fixed-pressure differential valves: a randomized, controlled study of programmable compared with conventional valves. Neurosurg Focus 7(4):e7, 1999

3. Eklund A, Koskinen LO, Williams MA, Luciano MG, Dombrowski SM, Malm J: Hydrodynamics of the Certas ${ }^{\mathrm{TM}}$ programmable valve for the treatment of hydrocephalus. Fluids Barriers CNS 9:12, 2012

4. Gupta N, Park J, Solomon C, Kranz DA, Wrensch M, Wu YW: Long-term outcomes in patients with treated childhood hydrocephalus. J Neurosurg 106 (5 Suppl):334-339, 2007

5. Hoppe-Hirsch E, Sainte Rose C, Renier D, Hirsch JF: Pericerebral collections after shunting. Childs Nerv Syst 3:97-102, 1987

6. Hoya K, Tanaka Y, Uchida T, Takano I, Nagaishi M, Kowata $\mathrm{K}$, et al: Treatment of traumatic acute subdural hematoma in adult hydrocephalus patients with cerebrospinal fluid shunt. Clin Neurol Neurosurg 114:211-216, 2012

7. Hydrocephalus Association: Adult Hydrocephalus Clinical Research Network. (http://www.hydroassoc.org/ahcrn/) [Accessed June 14, 2017]

8. Kay AD, Fisher AJ, O'Kane C, Richards HK, Pickard JD: A clinical audit of the Hakim programmable valve in patients with complex hydrocephalus. Br J Neurosurg 14:535-542, 2000
9. Lundkvist B, Eklund A, Koskinen LO, Malm J: An adjustable CSF shunt: advices for clinical use. Acta Neurol Scand 108:38-42, 2003

10. Lundkvist B, Koskinen LO, Birgander R, Eklund A, Malm J: Cerebrospinal fluid dynamics and long-term survival of the Strata valve in idiopathic normal pressure hydrocephalus. Acta Neurol Scand 124:115-121, 2011

11. Pachatouridis D, Alexiou GA, Mihos E, Fotakopoulos G, Voulgaris S: The value of programmable shunt valves for the management of subdural collections in patients with hydrocephalus. Sci World J 2013:461896, 2013

12. Richards HK, Seeley HM, Pickard JD: Efficacy of antibioticimpregnated shunt catheters in reducing shunt infection: data from the United Kingdom Shunt Registry. J Neurosurg Pediatr 4:389-393, 2009

13. Sæhle T, Farahmand D, Eide PK, Tisell M, Wikkelsö C: A randomized controlled dual-center trial on shunt complications in idiopathic normal-pressure hydrocephalus treated with gradually reduced or "fixed" pressure valve settings. J Neurosurg 121:1257-1263, 2014

14. Samuelson S, Long DM, Chou SN: Subdural hematoma as a complication of shunting procedures for normal pressure hydrocephalus. J Neurosurg 37:548-551, 1972

15. Steiner C, Elixhauser A, Schnaier J: The healthcare cost and utilization project: an overview. Eff Clin Pract 5:143-151, 2002

16. Sternbach GL: Subdural hematoma in a shunted patient. J Emerg Med 29:483-484, 2005

17. Sundström N, Malm J, Laurell K, Lundin F, Kahlon B, Cesarini $\mathrm{KG}$, et al: Incidence and outcome of surgery for adult hydrocephalus patients in Sweden. Br J Neurosurg 31:21-27, 2017

18. Toma AK, Papadopoulos MC, Stapleton S, Kitchen ND, Watkins LD: Systematic review of the outcome of shunt surgery in idiopathic normal-pressure hydrocephalus. Acta Neurochir (Wien) 155:1977-1980, 2013

19. Zemack G, Romner B: Adjustable valves in normal-pressure hydrocephalus: a retrospective study of 218 patients. Neurosurgery 51:1392-1402, 2002

20. Zemack G, Romner B: Seven years of clinical experience with the programmable Codman Hakim valve: a retrospective study of 583 patients. J Neurosurg 92:941-948, 2000

\section{Disclosures}

Drs. Sundström, Eklund, and Malm are inventors and report receiving royalties from Likvor $\mathrm{AB}$.

\section{Author Contributions}

Conception and design: Sundström, Lagebrant, Malm. Acquisition of data: Sundström, Lagebrant, Malm. Analysis and interpretation of data: all authors. Drafting the article: Lagebrant, Sundström. Critically revising the article: all authors. Reviewed submitted version of manuscript: all authors. Approved the final version of the manuscript on behalf of all authors: Sundström. Statistical analysis: Sundström, Lagebrant.

\section{Correspondence}

Nina Sundström, Department of Biomedical Engineering and Informatics, Umeå University Hospital, Umeå S-901 85, Sweden. email: nina.sundstrom@vll.se. 